Butcher, J. N., Graham, J. R., Dahlstrom, W. G., \& Bowman, E. (1990). The MMPI-2 with college students. Journal of Personality Assessment, 54, 1-15.

DAHLSTrom, W. G., WelSh, G. S., \& DAHLSTRom, L. E., (1972). An MMPI handbook (vol. 1). Minneapolis: University of Minnesota Press.

Friedman, A. F. (1990, March). MMPI-2 concerns [Letter to the editor]. APA Monitor, p. 2.

Graham, J. R. (1987). The MMPI: A practical guide (2nd ed.). New York: Oxford University Press.

Graham, J. R., Tmmbrook, R. E., \& Ben-Porath, Y. S. (in press). Code-type congruence between MMPI and MMPI-2: Separating fact from artifact. Journal of Personality Assessment.

Lubin, B., Larsen, R. M., Matarazzo, J. D., \& Seever, M. (1985). Psychological test usage patterns in five professional settings. American Psychologist, 40, 857-861.

Merenda, P. F. (1990, March). "Negative instance" error [Letter to the editor]. APA Monitor, pp. 2-3.

Piotrowski, C., \& Keller, J. W. (1989). Psychological testing in outpatient mental health facilities: A national study. Professional Psychology: Research and Practice, 20, 423-425.

\title{
RELIABILITY AND VALIDITY OF THE TURKISH VERSION OF THE AUTOMATIC THOUGHTS QUESTIONNAIRE
}

\author{
NESRIN H. ŞAHIN \\ Bilkent University \\ Ankara, Turkey \\ NAIL ŞAHIN \\ Middle East Technical University \\ Ankara, Turkey
}

\begin{abstract}
The present study investigated the reliability and validity of the ATQ in the Turkish cultural context. It is hoped that with this type of cross-cultural information, the universality of the proposed cognitive constructs can be advocated more reliably. The subjects were 345 university students; the splithalf reliability of the ATQ was found to be $r=.91$ and Cronbach's alpha was .93; and item/total correlations ranged between .36 and .69. The Turkish ATQ correlated well with the BDI $(r=.75)$, and it discriminated successfully between the symptomatic and asymptomatic groups. Factor analysis revealed five factors that were similar to those found in American samples. Nevertheless, some differences were noticed in the relative strength of the factors and in the distribution of items into factor clusters.
\end{abstract}

The role of cognition in the etiology, maintenance, and treatment of depression has been shown in various empirical studies in the last decade. The study of these cognitive factors in affective disorders, particularly in depression, and the outcome studies of several treatment procedures have pointed to the importance of certain maladaptive cognitive structures and negative self-statements (Harrell \& Ryon, 1983; Hollon \&

Correspondence should be addressed to Nesrin Şahin, Ph.D., Bilkent University, Psychological Counseling and Research Center, Lojmanlar Blok 20/5-6, Ankara, Turkey. 
Kendall, 1980; Kovacks \& Beck, 1978; Ross, Gottfredson, Christensen, \& Weaver, 1986; Simons, Murphy, Levine, \& Wetzel, 1984). Some of these cognitive factors are assumed to be at the trait level, and they are stable, underlying assumptions, schemas or irrational, deep structural beliefs. They are assumed to be rule-based and crosssituational. Others are, at the state or content level, situation-specific and unstable selfstatements (Dobson \& Shaw, 1986; Eaves \& Rush, 1984; Hollon, Kendall, \& Lumry, 1986).

In spite of considerable emphasis on the role of cognitive factors and the emergence of more than 15 cognitive behavior modification techniques, it is stated that little effort was made to assess those cognitive constructs mentioned in the literature and targeted by different therapeutic approaches (Clark, 1988; Hollon \& Kendall, 1980; Ross et al., 1986). These measures of cognition are classified into four methodological categories: the "recording" (think aloud), "production" (thought listing), "sampling," and "endorsement" methods. The last method, "endorsement," is used most frequently (Clark, 1988).

A review study on the validity of these cognitive measures has revealed that, in terms of the frequency of self-reported negative thoughts, the Automatic Thoughts Questionnaire (ATQ) is one of these endorsement approaches that successfully discriminates between clinical and nonclinical samples. It is presented as having high concurrent validity and is said to be sensitive to treatment effects (Clark, 1988). The items of the ATQ originally were gathered through a thought-listing procedure conducted on 788 university students. From this pool of items, 100 self-statements were selected and were tested with another group of 312 students. The 30 items that significantly discriminated between the depressed and nondepressed groups composed the Automatic Thoughts Questionnaire (ATQ). The ATQ was correlated with the BDI, the MMPI-D, and the STAI-A Trait and was found to have satisfactory concurrent validity. The reliability studies of the instrument were also satisfactory. The factor analysis revealed four factors, which explained $58.9 \%$ of the total variance. These were stated as: "Personal Maladjustment and Desire for Change," "Negative Self-concept and Negative Expectations," "Low Self-esteem," and "Giving up/Helplessness" (Hollon \& Kendall, 1980).

A study that investigated the reliability and validity of three cognitive assessment tools, the ATQ, DAS, and the Interpretation Inventory, with 466 university students found the ATQ to have notably higher internal reliability and closer correspondence to depression severity than the other two measures. It was evaluated as the instrument of choice for assessing cognitions in depression (Dobson \& Breiter, 1983).

Two studies on the clinical validation of the ATQ, which used various groups of patients, supported the ATQ's applicability to clinical populations. The clinically depressed patients were found to differ significantly in reported frequency of automatic negative thoughts (Harrell \& Ryon, 1983; Ross et al., 1986). Also, studies that investigated the specificity of several cognitive measures with regard to clinical depression showed that the ATQ demonstrated greater specificity to the syndrome of depression (Hollon et al., 1986; Ingram, Kendall, Smith, Donnell, \& Ronan, 1987).

Two studies investigated the reliability and validity of ATQ on clinical populations in Turkey. In these studies, depressed patients were compared to nondepressed control subjects, and the ATQ means were found to be significantly different (Aydin \& Aydin, 1988; Aytar, 1987). However, to date there are no studies on normal populations.

The purpose of the present study was to investigate the reliability and validity of the Automatic Thoughts Questionnaire (ATQ) and the Dysfunctional Attitude Scale (DAS) with university students. In addition, it is hoped that the investigation of the psychometric properties of these instruments in a different cultural setting will broaden their theoretical and empirical basis and will constitute additional evidence for the universality of the constructs they purport to measure. 


\section{METHOD}

\section{Subjects}

A total of 345 subjects participated in this study: 224 female and 101 male students at the Aegean University in Izmir, Turkey. The age range of students was between 19-21.

\section{Instruments}

The Automatic Thoughts Questionnaire (ATQ; Hollon \& Kendall, 1980) is a 30-item Likert-type questionnaire. The responses to the items can range between 1 (not at all) and 5 (all the time). The total score range can be between 30 and 150 . It was developed to measure the most frequent negative thoughts and negative self-evaluations associated with depression. The instrument has been used widely with clinical, adult, and college-student populations (Dobson \& Breiter, 1983; Harrell \& Ryon, 1983; Hollon \& Kendall, 1980; Ross et al., 1986). Spilt-half reliabilities range between $r=.96$ and $r=.97$. The Cronbach's alpha value was found to be .98 , and the item/total correlations ranged between $r=.47$ and $r=.78$ (Harrell \& Ryon, 1983; Hollon \& Kendall, 1980). In a study on the French version of the ATQ, the test-retest reliability was found to be $r=.71$ over a period of 15 days, and the Cronbach's alpha was .93 (Charles, Bouvard, Mollard, \& Cottraux, 1989). The validity studies of the ATQ revealed that the scale correlates highly with the BDI and with the MMPI-D; the correlation coefficients range between $r=.45$ to $r=.87$ and $r=.70$ to $r=.85$. The correlations of ATQ with the Dysfunctional Attitude Scale (DAS), STAI, the Hamilton Depression Scale, and the Interpretation Scale were $r=.53, r=.79, r=.80$, and $r=.43$, respectively (Deardorff, McIntosh, Adamek, Bier, \& Saalfeld, 1985; Dobson \& Breiter, 1983; Dobson \& Shaw, 1986; Harrell \& Ryon, 1983; Hollon \& Kendall, 1980; Hollon et al., 1986; Ross et al., 1986).

The discriminative validity studies of the instrument showed that it could discriminate successfully between the depressed and nondepressed groups (Hollon \& Kendall, 1980). A factor analysis on the French version revealed one main interpretable factor, which was termed "Negative Self-concept" (Charles et al., 1989).

The Beck Depression Inventory (BDI; Beck \& Steer, 1984; Beck, Ward, Mendelson, Mock, \& Erbaugh, 1961). This is a 21-item self-report inventory that measures the presence and severity of affective, cognitive, motivational, psychomotor, and vegetative manifestations of depression. The score range is $0-63$. The psychometric properties of the BDI are well known, and it is probably the most widely used research instrument in studies related to depression. In a previous study, one of the authors studied the psychometric properties of the Turkish version of the BDI (1978 Form). It was found to be a reliable and valid instrument to measure depression symptoms in clinical and student populations (Hisli, 1988).

The Dysfunctional Attitude Scale (DAS; Weissman \& Beck, 1978) consists of a pair of parallel-form 40-item scales designed to measure the more stable depressogenic assumptions or beliefs related to depression. It is reported to have high internal reliability, high correlation with other cognitive assessment measures, and sensitivity to depression (Dobson \& Breiter, 1983; Weissman \& Beck, 1978). The psychometric properties of the Turkish version of the DAS-A were investigated by the present authors, and it was found to have satisfactory reliability. The concurrent validity, using the BDI as the criterion measure, was found to be $r=17(p<.001)$ (Şahin \& Şahin, 1992).

\section{RESULTS}

The Turkish version of the ATQ used in this study was translated by the authors, and both the Turkish and the English forms were administered to 53 senior students in the English Department who speak both languages fluently. The order effect was controlled by giving the English ATQ to half of the group as the first instrument and the Turkish ATQ to the other half. The correlation between these two forms was found to be $r=.92$. 
The total group mean of the Turkish ATQ was found to be $52.84(S D=14.95)$. The split-half reliability was $r=.91$. The item/total correlations ranged between $r=.35$ and $r=.69$. Cronbach's alpha was .93. The correlation between the ATQ and the BDI was $r=.75(p<.001)$. These correlations are comparable to those mentioned in the literature (Dobson \& Breiter, 1983; Dobson \& Shaw, 1986; Harrell \& Ryon, 1983; Hollon \& Kendall, 1980; Hollon et al., 1986; Ross et al., 1986). Coefficients of comparable magnitude also were reported with Turkish clinical samples (Aydin \& Aydin, 1988; Aytar, 1987). The correlation between the ATQ and the DAS was $r=.27$, which was lower than found in other studies (Dobson \& Shaw, 1986; Hollon et al., 1986; Rush \& Weissenburger, 1986).

For the discriminative validity analysis, in accordance with Hollon and Kendall's procedure (1980), the subjects were categorized as nondepressed (BDI $<9$ ) and "depressed" (BDI > 17). These cutting points were found to be appropriate in the Turkish cultural context (Hisli, 1988). These groups were named "asymptomatic" and "symptomatic," as suggested by Beck, Steer, and Garbin (1988). The ATQ means and each ATQ item mean were compared between these extreme groups (Table 1).

Table 1

Discriminative Validity of ATQ Total Score and ATQ Items on a Sample of University Students

\begin{tabular}{|c|c|c|c|c|c|}
\hline & \multicolumn{2}{|c|}{$\begin{array}{c}\text { Asymptomatic } \\
\text { BDI }<9 \\
(n=155)\end{array}$} & \multicolumn{2}{|c|}{$\begin{array}{l}\text { Symtomatic } \\
\text { BDI > } 17 \\
(n=95)\end{array}$} & \multirow[b]{2}{*}{$t$} \\
\hline & $M$ & $S D$ & $M$ & $S D$ & \\
\hline ATQ total items & 43.85 & 8.47 & 67.56 & 16.29 & $15.10^{*}$ \\
\hline 1 & 1.30 & .48 & 1.99 & .99 & $7.34^{*}$ \\
\hline 2 & 1.19 & .40 & 1.69 & .85 & $6.30^{*}$ \\
\hline 3 & 1.54 & .53 & 2.13 & .90 & $6.54^{*}$ \\
\hline 4 & 1.78 & .58 & 2.73 & 1.07 & $9.05^{*}$ \\
\hline 5 & 1.80 & .53 & 2.21 & .74 & $5.10^{*}$ \\
\hline 6 & 1.28 & .61 & 1.96 & 1.02 & $6.61^{*}$ \\
\hline 7 & 1.66 & .87 & 2.16 & 1.10 & $3.94^{*}$ \\
\hline 8 & 1.45 & .56 & 2.33 & 1.03 & $8.71 *$ \\
\hline 9 & 1.94 & .74 & 2.79 & 1.05 & $7.54^{*}$ \\
\hline 10 & 1.50 & .65 & 2.28 & .99 & $7.56^{*}$ \\
\hline 11 & 1.45 & .59 & 2.43 & 1.21 & $8.61^{*}$ \\
\hline 12 & 1.32 & .52 & 2.31 & 1.17 & $9.18^{*}$ \\
\hline 13 & 1.71 & .66 & 2.32 & .98 & $5.82^{*}$ \\
\hline 14 & 1.70 & .71 & 2.51 & 1.06 & $7.14^{*}$ \\
\hline 15 & 1.88 & .82 & 2.93 & 1.21 & $8.09^{*}$ \\
\hline 16 & 1.39 & .53 & 2.07 & .97 & $7.17^{*}$ \\
\hline 17 & 1.07 & .28 & 1.92 & 1.04 & $9.58^{*}$ \\
\hline 18 & 1.07 & .26 & 1.79 & 1.04 & $8.21^{*}$ \\
\hline 19 & 1.16 & .35 & 2.08 & 1.20 & $8.92^{*}$ \\
\hline 20 & 1.41 & .58 & 2.21 & 1.11 & $7.45^{*}$ \\
\hline 21 & 1.26 & .55 & 2.15 & 1.16 & $8.20^{*}$ \\
\hline 22 & 1.52 & .67 & 2.68 & 1.21 & $9.81^{*}$ \\
\hline 23 & 1.44 & .54 & 2.18 & .97 & $7.78^{*}$ \\
\hline 24 & 1.22 & .50 & 1.81 & .98 & $6.29 *$ \\
\hline 25 & 1.48 & .64 & 2.52 & 1.07 & $9.55^{*}$ \\
\hline 26 & 2.04 & .82 & 3.25 & 1.21 & $9.44^{*}$ \\
\hline 27 & 1.14 & .37 & 1.86 & .94 & $8.54^{*}$ \\
\hline 28 & 1.23 & .42 & 2.13 & 1.09 & $9.13^{*}$ \\
\hline 29 & 1.63 & .88 & 2.19 & 1.18 & $4.02^{*}$ \\
\hline 30 & 1.33 & .50 & 2.15 & 1.04 & $8.35^{*}$ \\
\hline
\end{tabular}

${ }^{*} p<.001$ 
As it can be seen from Table 1, the ATQ as a whole, and each of the 30 items individually, can discriminate significantly $(p<.001)$ between the asymptomatic and symptomatic groups. These results are remarkably similar to those reported by Hollon and Kendall (1980). There were no significant differences between the scores of males $(n=101 ; M=54.46 ; S D=16.19)$ and females $(n=244 ; M=62.17, S D=14.39$; $t=1.30$ ). However, when the scale is taken item by item and analyzed in terms of gender, significant differences were found on items $1,9,10,23$, and 28. On these items, females obtained higher mean scores compared to males.

The factorial structure of the ATQ was explored through the principal component solution with iterations. According to the "eigenvalue greater than one" criterion, six factors were extracted that accounted for $57 \%$ of the total variance. After varimax rotation, five factors were found to be interpretable. Item loadings above .30 were accepted as the criterion for inclusion of an item into a factor. In cases in which an item had

Table 2

Factor Loadings of the ATQ Items

\begin{tabular}{|c|c|c|c|c|c|}
\hline \multirow[b]{2}{*}{ Items } & \multicolumn{5}{|c|}{ Factors } \\
\hline & 1 & 2 & 3 & 4 & 5 \\
\hline \multicolumn{6}{|l|}{ Negative Self-concept } \\
\hline 2 & .54 & & & & \\
\hline 3 & .63 & & & & \\
\hline 7 & .45 & & & & \\
\hline 8 & .40 & & & & \\
\hline 17 & .49 & & & & \\
\hline 18 & .65 & & & & \\
\hline 21 & .41 & & & & \\
\hline 23 & .55 & & & & \\
\hline 24 & .57 & & & & \\
\hline 27 & .36 & & & & \\
\hline \multicolumn{6}{|c|}{ Confusion and Escape Fantasies } \\
\hline 13 & & .30 & & & \\
\hline 14 & & .41 & & & \\
\hline 15 & & .44 & & & \\
\hline 19 & & .60 & & & \\
\hline 20 & & .61 & & & \\
\hline 22 & & .39 & & & \\
\hline \multicolumn{6}{|c|}{ Personal Maladjustment and Desire for Change } \\
\hline 9 & & & .59 & & \\
\hline 26 & & & .67 & & \\
\hline 29 & & & .44 & & \\
\hline \multicolumn{6}{|l|}{ Loneliness/Isolation } \\
\hline 1 & & & & .45 & \\
\hline 4 & & & & .41 & \\
\hline 10 & & & & .39 & \\
\hline 28 & & & & .52 & \\
\hline \multicolumn{6}{|l|}{ Giving up/Helplessness } \\
\hline 6 & & & & & .36 \\
\hline 11 & & & & & .46 \\
\hline 12 & & & & & .46 \\
\hline 25 & & & & & .43 \\
\hline$\%$ total variance & 35.1 & 5.9 & 4.4 & 3.9 & 3.9 \\
\hline$\%$ common variance & 71.9 & 9.1 & 5.9 & 4.9 & 4.4 \\
\hline
\end{tabular}


loadings of at least .30 and above over several factors, only the highest loading was retained in the interpretation of the factors. The five factors were named "Negative Self Concept," "Confusion/Escape Fantasies," "Personal Maladjustment and Desire for Change," "Loneliness/Isolation," and "Giving up and Helplessness." (See Table 2.)

In general, these analyses replicate the scale's factor structure as reported in the literature. However, there are considerable differences in the distribution of items into factors. In addition, the relative strength of the factors shows some differences. For example, the first factor in the Hollon and Kendall study (1980), "Personal Maladjustment and Desire for Change," is the strongest factor and explains $45.9 \%$ of the variance. In the present study, this dimension seems to be captured by the third factor, "Personal Maladjustment and Desire for Change," which explains $4.4 \%$ of the variance. Similarly, the first factor of the present study, "Negative Self-concept," which explains $35.1 \%$ of the variance, corresponds to Hollon and Kendall's (1980) second factor, which explained only $5.2 \%$ of the variance. An additional factor, named "Confusion and Escape Fantasies" (Factor 2), appeared in the present study. None of the items that defined this factor showed high loading on the Hollon and Kendall (1980) study. However, they accepted only loadings .50 or above for inclusion of an item into a factor.

\section{Discussion}

In general, the results of the present study demonstrate that the ATQ is a reliable and valid instrument to capture automatic negative thoughts in a different cultural context. The quantitative indices that pertain to internal consistency, construct validity, and the factor structure seem to be very similar to those reported with American samples. Item validity study based on extreme groups design revealed that all of the 30 items of the ATQ are highly discriminative in terms of depressive symptoms.

The remarkable similarity between the psychometric properties obtained in our study and those of Hollon and Kendall (1980) stands in striking contrast to the results with regard to the Turkish Version of the Dysfunctional Attitude Scale-DAS (Şahin $\&$ Şahin, in press). Through item validity studies and factor analyses, we have found that, compared to the American samples, the attitudinal orientation that co-exists with depressive symptoms was drastically different in the Turkish culture. For example, none of the so-called "reverse items" had discriminative power with Turkish university students. With the ATQ, however, the similarity between the two cultures in terms of the content of automatic thoughts and their co-existence with the dysphoric state is impressive.

From these findings one can extrapolate that, even though the structures of schemas that predispose individuals to depression may have been acquired on different pathways in different socio-cultural contexts, as was indicated in the results with the Turkish Dysfunctional Attitude Scale (Şahin \& Sahin, in press), the final depressed state in terms of self-related automatic negative thoughts may have generality across cultures. Further investigations are being planned with regard to the relative consistency in responding to items related to "negative self-concept" and "escape fantasies," which may be a reflection of culture-specific differences.

\section{REFERENCES}

AYDIN, G., A AYDIN, O. (1988). Otomatik Düşünceler Ölçeḡi'nin geçerlik ve güvenirliği (The reliability and validity of the ATQ). Psikoloji Dergisi, 7, 51-55.

AYTAR, G. (1987). Depresyondaki düşünce bozukluklarinin bilisssel kuram açisindan incelenmesi (An investigation of cognitive distortions in depression). Unpublished doctoral dissertation, Istanbul University Medical School.

BECK, A. T., STEER, R. A., (1984). Internal consistencies of the original and revised Beck Depression Inventories. Journal of Clinical Psychology, 40, 1365-1367. 
Beck, A. T., SteER, R. A., \& GarbIN, M. G. (1988). Psychometric properties of the Beck Depression Inventory: Twenty-five years of evaluation. Clinical Psychology Review, 8, 77-100.

Beck, A. T., Ward, C. H., Mendelson, M., Mock, J., \& ERbaugh, J. (1961). An inventory for measuring depression. Archives of General Psychiatry, 4, 561-571.

Charles, S., Bouvard, M., Mollard, E., \& CotTraux, J. (1989). Validation and factorial structure of the French version of the Automatic Thoughts Questionnaire. Poster presented at the World Congress of Cognitive Therapy, Oxford.

Clark, D. A. (1988). The validity of measures of cognition: A review of the literature. Cognitive Therapy and Research, 12, 1-20.

Deardorff, P. A., McIntosh, J. A., Adamek, C. A., Bier, M., \& SaAlfeld, S. (1985). Automatic Thoughts Questionnaire: A study of concurrent validity. Psychological Reports, 57, 831-834.

DOBSON, K. S., \& BREITER, H. J. (1983). Cognitive assessment of depression: Reliability and validity of three measures. Journal of Abnormal Psychology, 92, 107-109.

DOBson, K. S., \& SHAW, B. F. (1986). Cognitive assessment with major depressive disorders. Cognitive Therapy and Research, 10, 13-29.

EAves, G., \& Rush, A. J. (1984). Cognitive patterns in symptomatic and remitted unipolar major depression. Journal of Abnormal Psychology, 93, 31-40.

HARREL, T. H., \& RYON, N. B. (1983). Cognitive-behavioral assessment of depression: Clinical validation of the Automatic Thoughts Questionnaire. Journal of Consulting and Clinical Psychology, 51, 721-725.

Hısı, N. (1988). Beck Depression Envarteri'nin Üniversite öğrencileri için geçerliği güvenirliği (Reliability and validity of the BDI with a group of university students). Psikoloji Dergisi, 7, 3-13.

Hollon, S. D., \& Kendalı, P. C. (1980). Cognitive self-statements in depression: Development of an Automatic Thoughts Questionnaire. Cognitive Therapy and Research, 4, 383-395.

Hollon, S. D., KENDALl, P. C., \& LUMRY, A. (1986). Specificity of depressotypic cognitions in clinical depression. Journal of Abnormal Psychology, 95, 52-59.

Ingram, R. E., Kendall, P. C., Smith, T. W., Donnell, C., \& Ronan, K. (1987). Cognitive specificity in emotional distress. Journal of Personality and Social Psychology, 53, 734-742.

Kovacks, M., \& BECK, A. T. (1978). Maladaptive cognitive structures in depression. American Journal of Psychiatry, 135, 525-533.

Ross, S. M., Gottfredson, D. K., Christensen, P., \& Weaver, R. (1986). Cognitive self-statements in depression: Findings across clinical populations. Cognitive Therapy and Research, 10, 159-166.

Rush, A. J., \& Weissenguraer, J. (1986). Do thinking patterns predict depressive symptoms? Cognitive Therapy and Research, 10, 225-236.

SAHIN, N. H., \& SAHIN, N. (1992). How dysfunctional are the dysfunctional attitudes in another culture? British Journal of Medical Psychology, 65, 17-26.

Smons, A., MuRPhY, G. E., LeVINE, J., \& WeTzEL, R. (1984). Sustained improvement one year after cognitive and/or pharmacotherapy of depression. Paper presented at the meeting of Society of Psychotherapy Research, Lake Louise.

Weissman, A. N., Beck, A. T. (1978). Development and validation of the Dysfunctional Attitude Scale: A preliminary investigation. Paper presented at the annual meeting of the American Educational Research Association, Toronto. 